\title{
SPECIFIC EXERGY COSTING ANALYSIS AND OPTIMIZATION OF CCPP POWER PLANT
}

\section{Dr. MOHAMMED SALEH MOHAMMED \& Dr. TAHA AHMED ABDULLAH}

Lecturer, Department of Mechanical, Engineering College, Mosul University, Mosul, Iraq

\begin{abstract}
There are different methodologies for calculating exergy costs and efficiencies for combined cycle power plant. In current work modified specific exergy costing (SPECO) are applied. Based on SPECO approach the cost and exergy stable equations are worked out and the exergoeconomic analysis are performed. Exergy and energy examinations regarding triple pressure integrated cycle power plant are applied to decide the exergoeconomic variables for whole system and the elements, auxiliary equations and cost balance equations are developed. Exergoeconomic optimization by simple method for six operating parameters of the bottoming cycle is conducted. A comparison between the result of exergoeconomic optimization and initial case shows that the reduction in total cost per hour by this method is $31.5 \%$. The result shows an improvement in the thermodynamic performance and exergoeconomic parameters by applying new optimum operating parameters

KEYWORDS: Exergy, Exergoeconomic optimization \& SPECO
\end{abstract}

Received: Oct 07, 2019; Accepted: Oct 27, 2019; Published: Mar 19, 2020; Paper Id.: IJMPERDDEC201998

\section{INTRODUCTION}

Due to the rise on fossil fuel prices, the environmental effect during their use and the external energetic dependency on instable nations, it turns highly crucial to recognize the procedure that degenerate energy and sources. In the design of integrated cycle power plant or any thermal system the first essential and interested subjective was optimization. Therefore, knowing optimum conditions of power plant or any other thermal system is very important.

"Exergoeconomic (Thermoeconomic) is the branch of engineering that combines exergy analysis with economic constraints to provide the system designer with information not available through conventional energetic analysis and economic evaluation" Sahoo [1]. The objectives of Themoeconomic studies are, understanding the flow of cost and cost formation in the system, based on the calculations of every product-created cost by a structure Tsatsaronis and Moran [2], Much researcher has been studied the exergoeconomic performance of thermal system.

Sahoo [1] studied an exergoeconomic study by the developmental programming of a cogeneration structure; he concluded that the optimum condition gives product cost lower by $9.9 \%$ than that of the core instance. This result obtained with increased investment cost for 10\%. Abusoglu and Kanoglu [3] investigate an exergoeconomic study and maximum effective of integrated heat and power systems, considering different optimization methods. Baghernejad and Yaghoubi [7] considered an Integrated Solar combined cycle system (ISCCS), employing genetic algorithm; he provided a review for exergoeconomic analysis and optimization of (ISCCS). 


\section{SYSTEM DESCRIPTION}

The main components of the structure in the research are depicted in figure 1 . The integrated cycle power unit mainly consists of high temperature recuperation steam initiator steam turbine condenser and gas turbine.

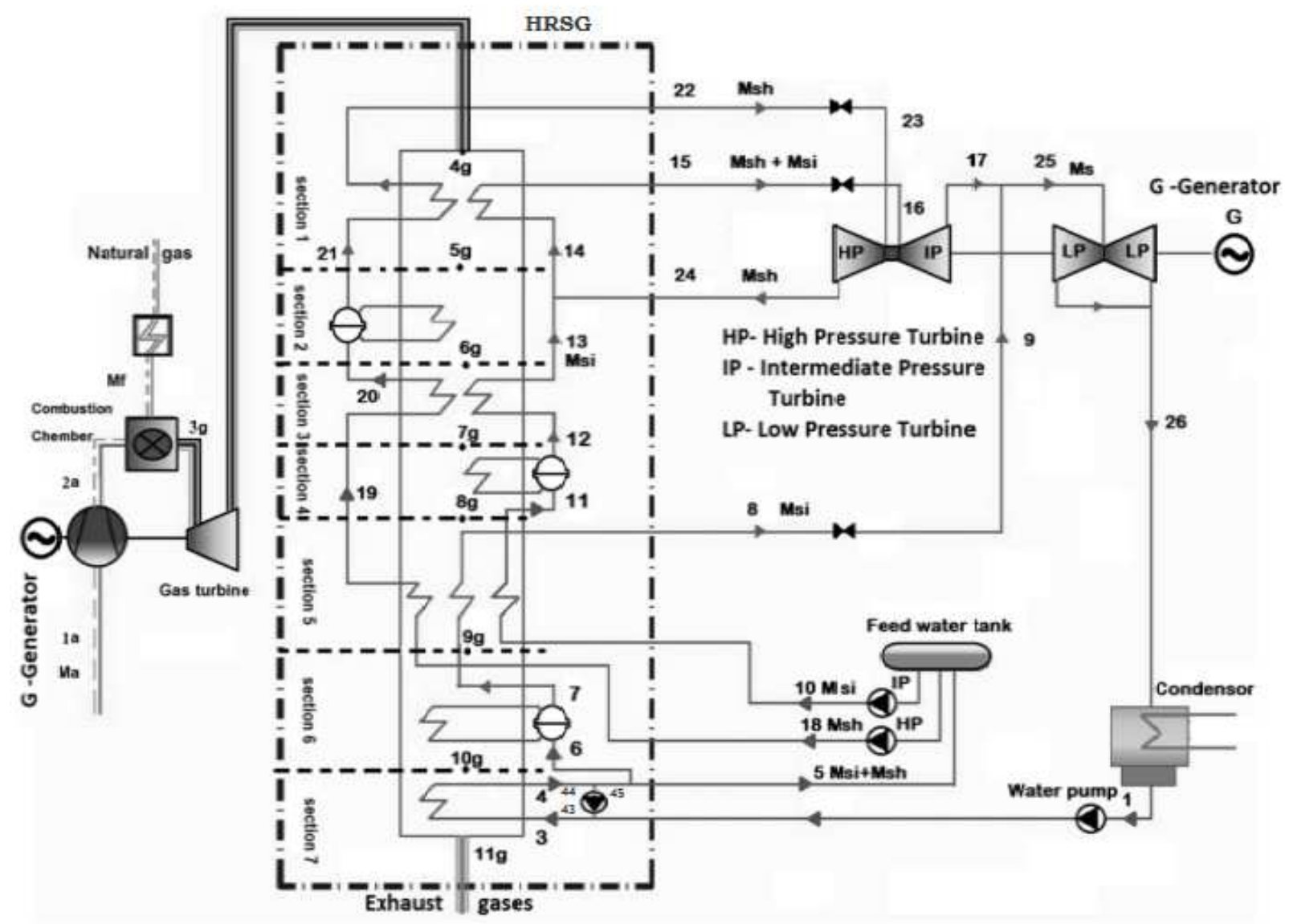

Figure 1: A Schematic Diagram of the Triple Pressure Combined Cycle Power Plant.

\section{EXERGOECONOMIC ANALYSIS}

Incorporations of economic laws into thermodynamic analysis or precisely exergy analysis, at a degree of technique component, in accordance to give data for engineers to cost- effectively model is that branch of engineering called exergoeconomic.

Current study implies, the SPECO (specific exergy costing) technique is employed. This method combines exergetic and economic properties; The base factors of this method are, cost per unit exergy, specific exergies, exergy efficiency and auxiliary equations (cost equations) for element of combined cycle. This method includes three main processes:

\section{Quantifying the Energy and Exergy Streams}

As a first step in this method is energy and exergy analysis, this analysis performed based on energy and exergy conservation equations, beside the exergy balance to every element of the system [5].

$$
\sum \dot{m}_{i}=\sum \dot{m}_{e}
$$




$$
\begin{aligned}
& \dot{Q}+\sum \dot{m}_{i} h_{i}=\dot{W}+\sum \dot{m}_{e} h_{e} \\
& \dot{E}_{Q}+\sum \dot{m}_{i} \dot{e}_{i}=\dot{E}_{W}+\sum \dot{m}_{e} \dot{e}_{e}+\dot{E}_{D}
\end{aligned}
$$

where is $\mathrm{m}_{i}$ and $\mathrm{m}_{e}$ are the mass inlet and outlet, $\dot{E}_{D}$ is the exergy elimination value in the system element, $\dot{E}_{Q}$ is the exergy rate corresponding to high temperature transfer rate, i.e. $\dot{E}_{Q}=\left(1-T_{o} / T_{i}\right) \dot{Q}_{i}$, and $\dot{E}_{W}$ is the exergy rate of the mechanical power, i.e. $\dot{E}_{W}=\dot{W} \cdot \dot{Q}$ refer to the heat rate and $\dot{W}$ to the work rate, while $T_{o}$ is the average temperature. The equation applied to the physical exergy is [6]:

$$
e^{P H}=\left(h-h_{o}\right)+T_{o}\left(s-s_{o}\right)
$$

Total exergy of each stream equal to the product of specific exergy and its corresponding mass flow rate. Applying continuity equations, initial and subsequent rules of thermodynamics, and exergy efficiency equation Eq.5, the exergy destruction $\dot{E}_{D}$ could easily acquired. Table 1 Indicates the equations of every element of the method

$$
\varepsilon=\frac{\sum \Delta \dot{E}_{\text {out }}}{\sum \Delta \dot{E}_{\text {in }}} \varepsilon=1-\frac{I_{r}}{\sum \dot{E}_{\text {in }}}
$$

Where $I_{r}$ is the irreversibility.

Table 1: The Exergy Destruction Rate and Exergy Efficiency for the Main Components of the System

\begin{tabular}{|l|c|c|}
\hline \multicolumn{1}{|c|}{ Component } & Exergy Destruction & Exergy Efficiency \\
\hline Steam turbine & $\dot{E}_{D, S T}=\dot{E}_{22}+\dot{E}_{15}+\dot{E}_{8}-\dot{E}_{24}-\dot{E}_{26}-\dot{E}_{S T}$ & $\varepsilon_{S T}=\frac{\dot{E}_{S T}}{\dot{E}_{16}+\dot{E}_{23}+\dot{E}_{9}-\dot{E}_{26}-\dot{E}_{24}}$ \\
\hline HRSG & $\begin{array}{l}\dot{E}_{D, H R S G}=\dot{E}_{4 g}+\dot{E}_{24}+\dot{E}_{18}+\dot{E}_{10}+\dot{E}_{2}-\dot{E}_{22} \\
-\dot{E}_{15}-\dot{E}_{8}-\dot{E}_{5}-\dot{E}_{11 g}\end{array}$ & $\varepsilon_{H R S G}=1-\frac{\dot{E}_{D, H R S G}}{\dot{E}_{4 g}}$ \\
\hline Condenser & $\dot{E}_{D, C o n}=\dot{E}_{26}-\dot{E}_{1}$ & $\varepsilon_{C o n}=1-\frac{\dot{E}_{1}}{\dot{E}_{26}}$ \\
\hline \multicolumn{1}{c}{ Total } & $\dot{E}_{D, T O T}=\dot{E}_{D, H R S G}+\dot{E}_{D, S T}+\dot{E}_{D, C o n}$ & $\varepsilon_{T O T}=1-\frac{\dot{E}_{D, T O T}+\dot{E}_{11 g}}{\dot{E}_{4 g}}$ \\
\hline
\end{tabular}

\section{Definition of Fuel and Product for Every Element of Thermal System}

The fuel is a necessary resource to produce the output by system or component and this input is not necessary to be a real fuel like coal, oil, natural gas. The invention is the outcome or wanted result that the method generated or component.

\begin{tabular}{|c|c|c|c|}
\hline Component & & Fuel Exergy Rate $\dot{E}_{F}$ & Production Exergy Rate $\dot{E}_{P}$ \\
\hline \multirow{2}{*}{$\begin{array}{l}0 \\
\mathscr{W} \\
\underline{I}\end{array}$} & Section1 & $\dot{E}_{4 g}-\dot{E}_{5 g}$ & $\dot{E}_{22}-\dot{E}_{21}+\dot{E}_{15}-\dot{E}_{14}$ \\
\hline & Section2 & $\dot{E}_{5 g}-\dot{E}_{6 g}$ & $\dot{E}_{21}-\dot{E}_{20}$ \\
\hline
\end{tabular}
Product and fuel are in term of exergy [7].

Table 2 gives the exergy equations of fuels $\dot{E}_{F}$ and generates $\dot{E}_{P}$ for each component of the method.

Table 2: The Definitions of the Exergy of Fuel, Exergy of Product 


\begin{tabular}{|c|c|c|c|}
\hline & Section3 & $\dot{E}_{6 g}-\dot{E}_{7 g}$ & $\dot{E}_{20}-\dot{E}_{19}+\dot{E}_{13}-\dot{E}_{12}$ \\
\cline { 2 - 4 } & Section4 & $\dot{E}_{7 g}-\dot{E}_{8 g}$ & $\dot{E}_{12}-\dot{E}_{11}$ \\
\cline { 2 - 4 } & Section5 & $\dot{E}_{8 g}-\dot{E}_{9 g}$ & $\dot{E}_{8}-\dot{E}_{7}+\dot{E}_{11}-\dot{E}_{10}+\dot{E}_{19}-\dot{E}_{18}$ \\
\cline { 2 - 4 } & Section6 & $\dot{E}_{9 g}-\dot{E}_{10 g}$ & $\dot{E}_{7}-\dot{E}_{6}$ \\
\cline { 2 - 4 } & Section7 & $\dot{E}_{10 g}-\dot{E}_{11 g}$ & $\dot{E}_{4}-\dot{E}_{3}$ \\
\hline \multirow{3}{*}{ Steam turbine pressure level } & High & $\dot{E}_{23}-\dot{E}_{24}$ & $P_{S T, H P}$ \\
\cline { 2 - 4 } & Intermediate & $\dot{E}_{16}-\dot{E}_{17}$ & $P_{S T, I P}$ \\
\cline { 2 - 4 } & low & $\dot{E}_{25}-\dot{E}_{26}$ & $P_{S T, L P}$ \\
\hline Condenser & & $\dot{E}_{26}-\dot{E}_{1}$ & $\dot{E}_{w 2}-\dot{E}_{w 1}$ \\
\hline Feed water tank & $P_{\text {pump }, H P}+P_{p u m p, L P}$ & $\dot{E}_{18}+\dot{E}_{10}-\dot{E}_{5}$ \\
\hline Condenser pump & $P_{\text {pump }, C O N}$ & $\dot{E}_{2}-\dot{E}_{1}$ \\
\hline \multicolumn{2}{|c|}{} & &
\end{tabular}

\section{COST BALANCE}

Cost balance equation Eq.6 implied to each component ( $\mathrm{k}^{\text {th }}$ element) of this system. Eq.6 shows the equality between summation of input exergy cost value as well output exergy cost value plus the capital investment cost rate with all costs for maintenance and operating $\dot{Z}_{k}[7]$.

$$
\begin{aligned}
& \sum_{e} \dot{C}_{e, k}+\dot{C}_{w, k}=\dot{C}_{q, k}+\sum_{i} \dot{C}_{i, k}+\dot{Z}_{k} \\
& \dot{C}_{j}=c_{j} \dot{E}_{j}
\end{aligned}
$$

Where, $\dot{C}(\$ / \mathrm{s})$ is the flow cost rate, subscripts $e$ and $i$ are the entering as well exiting streams for $\mathrm{k}^{\text {th }}$ component. There are several methods for calculating $\dot{Z}_{k}$ in terms of model parameters, in this work Eq. 8 is applied for transforming the capital investment to cost per time unit.

$$
\dot{Z}_{k}=\frac{Z_{k} C R F \varphi}{3600 N}
$$

where $Z_{k}$ is the purchase cost function of $k^{\text {th }}$ component in dollar [5],CRF is the capital recovery factor, $N, \varphi$ are number of operating hours in year and maintenance factor respectively.

The investment recuperation factor $C R F$ is a basis of the interest rate as well estimated component lifetime, it was determined using eq. 9, [10]:

$$
C R F=\frac{i(1+i)^{n}}{(1+i)^{n}-1}
$$

where $i$ is the interest rate and $n$ is the total operating period of the method in certain period.

Table 3: Exergetic Cost Balances and Auxiliary Equations for the Bottoming Cycle Power Plant

\begin{tabular}{l|l|l} 
Component & Exergetic Cost Rate Balance Main & Additional Equations \\
\hline
\end{tabular}




\begin{tabular}{|c|c|c|c|}
\hline & Equation & P rule & F rule \\
\hline HRSG Section 1 & $\begin{array}{l}\dot{C}_{4 g}+\dot{C}_{21}-\dot{C}_{22}-\dot{C}_{5 g}+\dot{C}_{14} \\
-\dot{C}_{15}=-\dot{Z}_{s u, H P}-\dot{Z}_{R H}\end{array}$ & $\begin{array}{l}\frac{\dot{C}_{15}-\dot{C}_{14}}{\dot{E}_{15}-\dot{E}_{14}}=c_{p 1} \\
\frac{\dot{C}_{22}-\dot{C}_{21}}{\dot{E}_{22}-\dot{E}_{21}}=c_{p 1}\end{array}$ & $\frac{\dot{C}_{4 g}}{\dot{E}_{4 g}}=\frac{\dot{C}_{5 g}}{\dot{E}_{5 g}}$ \\
\hline HRSG Section 2 & $\dot{C}_{5 g}+\dot{C}_{20}-\dot{C}_{21}-\dot{C}_{6 g}=-\dot{Z}_{e v}, H P$ & & $\frac{\dot{C}_{5 g}}{\dot{E}_{5 g}}=\frac{\dot{C}_{6 g}}{\dot{E}_{6 g}}$ \\
\hline HRSG Section3 & $\begin{array}{l}\dot{C}_{6 g}+\dot{C}_{19}-\dot{C}_{20}-\dot{C}_{7 g}+\dot{C}_{12} \\
-\dot{C}_{13}=-\dot{Z}_{e c 2, H P}-\dot{Z}_{s u, I H}\end{array}$ & $\begin{array}{l}\frac{\dot{C}_{20}-\dot{C}_{19}}{\dot{E}_{20}-\dot{E}_{19}}=c_{p 2} \\
\frac{\dot{C}_{13}-\dot{C}_{12}}{\dot{E}_{13}-\dot{E}_{12}}=c_{p 2}\end{array}$ & $\frac{\dot{C}_{6 g}}{\dot{E}_{6 g}}=\frac{\dot{C}_{7 g}}{\dot{E}_{7 g}}$ \\
\hline HRSG Section 4 & $\dot{C}_{7 g}+\dot{C}_{11}-\dot{C}_{12}-\dot{C}_{8 g}=-\dot{Z}_{e v, I P}$ & & $\frac{\dot{C}_{7 g}}{\dot{E}_{7 g}}=\frac{\dot{C}_{8 g}}{\dot{E}_{8 g}}$ \\
\hline HRSG Section 5 & $\begin{array}{l}\dot{C}_{8 g}+\dot{C}_{18}-\dot{C}_{19}-\dot{C}_{9 g}+\dot{C}_{10}-\dot{C}_{11} \\
+\dot{C}_{7}-\dot{C}_{8}=-\dot{Z}_{e c 1, H P}-\dot{Z}_{e c, I P}-\dot{Z}_{s u, L P}\end{array}$ & $\begin{array}{l}\frac{\dot{C}_{19}-\dot{C}_{18}}{\dot{E}_{19}-\dot{E}_{18}}=c_{p 3} \\
\frac{\dot{C}_{11}-\dot{C}_{10}}{\dot{E}_{11}-\dot{E}_{10}}=c_{p 3} \\
\frac{\dot{C}_{8}-\dot{C}_{7}}{\dot{E}_{8}-\dot{E}_{7}}=c_{p 3}\end{array}$ & $\frac{\dot{C}_{8 g}}{\dot{E}_{8 g}}=\frac{\dot{C}_{9 g}}{\dot{E}_{9 g}}$ \\
\hline HRSG Section 6 & $\dot{C}_{9 g}+\dot{C}_{6}-\dot{C}_{7}-\dot{C}_{10 g}=-\dot{Z}_{e v, L P}$ & & $\frac{\dot{C}_{9 g}}{\dot{E}_{9 g}}=\frac{\dot{C}_{10 g}}{\dot{E}_{10 g}}$ \\
\hline HRSG Section 7 & $\dot{C}_{10 g}+\dot{C}_{2}-\dot{C}_{4}-\dot{C}_{11 g}=-\dot{Z}_{e c, L P}$ & & $\frac{\dot{C}_{10 g}}{\dot{E}_{10 g}}=\frac{\dot{C}_{11 g}}{\dot{E}_{11 g}}$ \\
\hline High pressure steam turbine & $\dot{C}_{22}-\dot{C}_{24}-\dot{C}_{S T, H P}=-\dot{Z}_{S T, H P}$ & & $\frac{\dot{C}_{23}}{\dot{E}_{23}}=\frac{\dot{C}_{24}}{\dot{E}_{24}}$ \\
\hline $\begin{array}{l}\text { Intermediate pressure steam } \\
\text { turbine }\end{array}$ & $\dot{C}_{15}-\dot{C}_{17}-\dot{C}_{S T, I P}=-\dot{Z}_{S T, I P}$ & & $\frac{\dot{C}_{16}}{\dot{E}_{16}}=\frac{\dot{C}_{17}}{\dot{E}_{17}}$ \\
\hline Low pressure steam turbine & $\dot{C}_{25}-\dot{C}_{26}-\dot{C}_{S T, L P}=-\dot{Z}_{S T, L P}$ & & $c_{25}=c_{26}$ \\
\hline Condenser & $\dot{C}_{26}+\dot{C}_{w 1}-\dot{C}_{1}-\dot{C}_{w 2}=-\dot{Z}_{C O N}$ & & $\frac{\dot{C}_{26}}{\dot{E}_{26}}=\frac{\dot{C}_{1}}{\dot{E}_{1}}$ \\
\hline Mixing of stream $2 \& 43$ & $\dot{C}_{2}+\dot{C}_{43}=\dot{C}_{3}$ & & \\
\hline Feed water tank & $\begin{array}{l}\dot{C}_{5}+\dot{C}_{\text {pump }, I P}+\dot{C}_{p u m p, H P} \\
-\dot{C}_{10}-\dot{C}_{18}=-\dot{Z}_{F W T}\end{array}$ & $\frac{\dot{C}_{10}}{\dot{E}_{10}}=\frac{\dot{C}_{18}}{\dot{E}_{18}}$ & \\
\hline Splitting of streams $43 \& 45$ & $\dot{C}_{4}=\dot{C}_{43}+\dot{C}_{45}$ & $\frac{\dot{C}_{43}}{\dot{E}_{43}}=\frac{\dot{C}_{45}}{\dot{E}_{45}}$ & \\
\hline Fed water pump & $\dot{C}_{1}+\dot{C}_{\text {pump }, \text { CON }}-\dot{C}_{2}=-\dot{Z}_{\text {pump }}$ & & \\
\hline $\begin{array}{l}\text { Mixing of streams } \\
13 \& 14\end{array}$ & $\dot{C}_{24}+\dot{C}_{13}=\dot{C}_{14}$ & & \\
\hline Splitting of streams $5 \& 6$ & $\dot{C}_{45}=\dot{C}_{5}+\dot{C}_{6}$ & & $\frac{\dot{C}_{5}}{\dot{E}_{5}}=\frac{\dot{C}_{6}}{\dot{E}_{6}}$ \\
\hline Mixing of stream 8 \& 17 & $\dot{C}_{8}+\dot{C}_{17}=\dot{C}_{25}$ & & \\
\hline
\end{tabular}


The costs of the unknown streams were determined by figuring out the method of linear equations in table 3.

The parameters in table 4 have significant impact over exergoeconomic analysis of integrated cycle power unit. These parameter are the exergy destruction cost rate $\left(\dot{C}_{D}\right)$, the fuel $\left(c_{F, k}\right)$ average cost per unit exergy, the product $\left(c_{P, k}\right)$ average cost per unit exergy, the relative cost difference $\left(r_{k}\right)$ and the exergoeconomic factor $\left(f_{k}\right)$. The parameters are computed in a following manner [8]:

Table 4: Exergoeconomic Parameter

\begin{tabular}{|c|c|c|c|c|}
\hline$c_{F, k}$ & $c_{P, k}$ & $\dot{C}_{D, k}$ & $r_{k}$ & $f_{k}$ \\
\hline$c_{F, k}=\frac{\dot{C}_{F, k}}{\dot{E}_{F, k}}$ & $c_{P, k}=\frac{\dot{C}_{P, k}}{\dot{E}_{P, k}}$ & $\dot{C}_{D, k}=c_{F, k} \dot{E}_{D, k}$ & $r_{k}=\frac{c_{P, k}-c_{F, k}}{c_{F, k}}$ & $f_{k}=\frac{\dot{Z}_{k}}{\dot{Z}_{k}+\dot{C}_{D, k}+\dot{C}_{L, k}}$ \\
\hline
\end{tabular}

The relative cost difference $r_{k}$ reports the variability among these particular product and fuel cost of every element. Such variability is because of a cost rate of exergy elimination $\left(\dot{C}_{D, k}\right)$ and the cost rate related with the capital cost $\left(\dot{Z}_{k}\right)$ [8]. The exergoeconomic element $f_{k}$ was the criterion that indicates the parallel significance of a element cost to the cost of exergy elimination and depletion related with the element

\section{EXERGOECONOMIC OPTIMIZATION}

Commonly, a thermal power plant has two contradictory objectives:- one being decreased and other is increased, costs to be decreased, while, thermal and exergy productivity should increased. The aim of optimization is for fulfill all goals. Cost purpose was limited because of economic constrains, while the efficiencies are regulated by thermodynamic requirements. Hence, a major purpose must choose particularly where a result of maximization fulfills all contradictory prerequisites [7].

In this, work the objective function defined by Eq. 10 [9], which is the total specific unit cost of product $c_{P, T O T}$.

$$
c_{P, T O T}=\frac{\sum_{k=1}^{n k} \dot{Z}_{k}+\sum_{k=1}^{N F} c_{F, k} \dot{E}_{F, k}}{\sum_{k=1}^{N P} \dot{E}_{P, k}}
$$

Where is, $n k$, NF and NP amount of system elements, number of system fuel, stream as well number of system product stream respectively.

The exergoeconomic performance of integrated cycle power unit relies upon following decision variables: (i) pinch point degree in the evaporators, (ii) force drum for a low, intermediate, as well high-pressure level. Hence, the maximization issue could conveyed as a purpose of six determination variables minimize $c_{P, T O T}(P P L, P P I, P P H, L P, I P, H P)$. In this work constrains are; the higher margin of the high load drum $H P \leq 180$ bar, an exhaust gas temperature $T_{11 g}$ lower limit $T_{11 g} \geq 93{ }^{\circ} \mathrm{C}$ and pinch point temperature lower limit $P P \geq 4{ }^{\circ} \mathrm{C}$

\section{RESULT AND DISCUSSIONS}


The influence of performing criterions on the factor exergy cost of the net generated power $c_{P, T O T}$ as well the results of optimization are presented in Figs. (2-7). Error! Reference source not found. shows the lower limit of $P P L=14{ }^{\circ} \mathrm{C}$ because the constrain of the exhaust gas temperature $T_{11 g}$. Error! Reference source not found. shows the lower limit of $P P I=4{ }^{\circ} \mathrm{C}$ because of the pinch point constrain, Error! Reference source not found. shows the optimal value of the high pressure pinch point $P P H=17^{\circ} \mathrm{C}$. The results shown in Figs. 6-7 represent the optimum performance condition at pressure drum of $I P=37$ bar and $H P=175$ bar . There is a constrain regarding low pressure drum (exhaust gas temperature $T_{11 g}$ ), therefore, the upper limit of $L P=4$ bar . In Error! Reference source not found.,

The major significant element of an exergoeconomic outlook is HRSG, because it have a largest $\dot{Z}_{k}+\dot{C}_{D}$ and low exergoeconomic factor $f_{k}$, that is an sign of the respective importance of exergy elimination and capital investment costs. The subsequent largest value of $\dot{Z}_{k}+\dot{C}_{D}$ connects to steam turbine. Error! Reference source not found. indicates the outcome of maximization, exergoeconomic criterions of the primary elements of the bottoming cycle for the optimum case. As it is shown, the value of $\dot{Z}_{k}+\dot{C}_{D}$ and the exergoeconomic factor of all elements has increased after optimization proposing that by reducing the exergy destruction cost and raising exergetic potentiality of the tool via higher investment costs, the total cost can be saved.

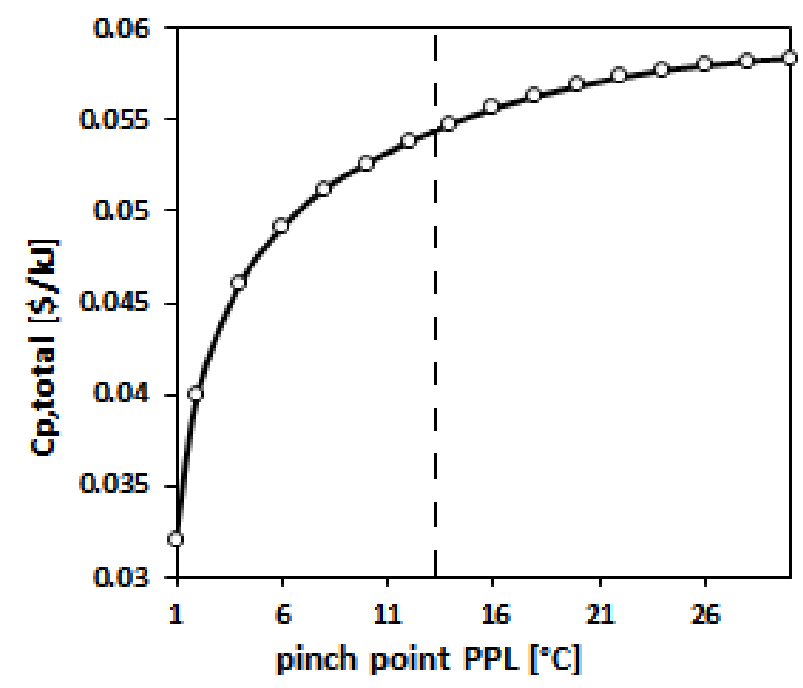

Figure 1: Low Pressure Pinch Point PPL vs. Objective Function. 


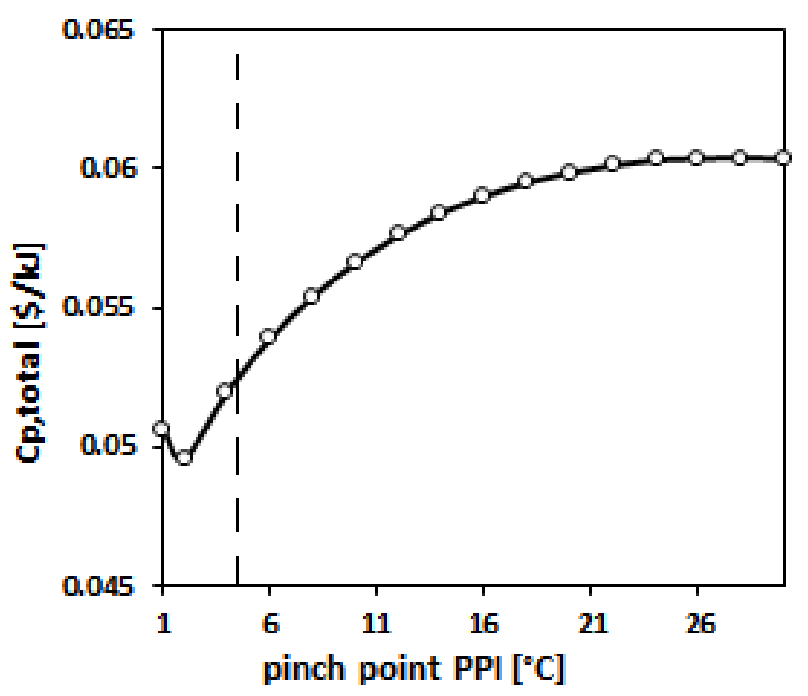

Figure 2: Intermediate Pressure Pinch Point PPI vs. Objective Function.

Table 5: Exergoeconomic Parameters of the System for the Initial Case

\begin{tabular}{|l|c|c|c|c|c|c|c|c|}
\hline & $\begin{array}{c}\dot{E}_{F, k} \\
{[\mathbf{k W}]}\end{array}$ & $\begin{array}{c}\dot{E}_{P, k} \\
{[\mathbf{k W}]}\end{array}$ & $\begin{array}{c}\dot{E}_{D, k} \\
{[\mathbf{k W}]}\end{array}$ & $\begin{array}{c}\dot{C}_{D, k} \\
{[\$ / \mathbf{h}]}\end{array}$ & $\begin{array}{c}\dot{Z}_{k} \\
{[\$ / \mathbf{h}]}\end{array}$ & $\dot{Z}_{k}+\dot{C}_{D, k}[\mathbf{\$} / \mathbf{h}]$ & $\begin{array}{c}\varepsilon_{k} \\
{[\%]}\end{array}$ & $\begin{array}{c}f_{k} \\
{[\%]}\end{array}$ \\
\hline HRSG & 186365 & 161663 & 24702 & 1483.92 & 677.11 & 2161.03 & 86.745 & 31.333 \\
\hline Condenser & 10909 & 3839 & 7070 & 430.34 & 95.41 & 525.75 & 96.929 & 12.563 \\
\hline FWT & 1938 & 1391 & 547 & 41.12 & 23.68 & 64.8 & 71.784 & 36.538 \\
\hline Steam turbine & 149356 & 134544 & 14812 & 904.18 & 925.1 & 1829.28 & 90.083 & 50.572 \\
\hline \multicolumn{1}{|c|}{ Total } & $\mathbf{1 8 6 3 6 5}$ & $\mathbf{1 3 4 5 4 4}$ & $\mathbf{4 9 9 9 7}$ & $\mathbf{3 0 0 3 . 4}$ & $\mathbf{1 8 5 2 . 4}$ & $\mathbf{4 8 5 5 . 8 4}$ & $\mathbf{7 3 . 1 7 3}$ & $\mathbf{3 8 . 1 4 8}$ \\
\hline
\end{tabular}

Table 6: Exergoeconomic Parameters of the System for the Optimum Case

\begin{tabular}{|l|c|c|c|c|c|c|c|c|}
\hline & $\begin{array}{c}\dot{E}_{F, k} \\
{[\mathbf{k W}]}\end{array}$ & $\begin{array}{c}\dot{E}_{P, k} \\
{[\mathbf{k W}]}\end{array}$ & $\begin{array}{c}\dot{E}_{D, k} \\
{[\mathbf{k W}]}\end{array}$ & $\begin{array}{c}\dot{C}_{D, k} \\
{[\mathbf{\$} / \mathbf{h}]}\end{array}$ & $\begin{array}{c}\dot{Z}_{k} \\
{[\mathbf{\$} / \mathbf{h}]}\end{array}$ & $\dot{Z}_{k}+\dot{C}_{D, k}[\mathbf{\$} / \mathbf{h}]$ & $\begin{array}{c}\varepsilon_{k} \\
{[\%]}\end{array}$ & $\begin{array}{c}f_{k} \\
{[\%]}\end{array}$ \\
\hline HRSG & 186515 & 165637 & 20878 & 549.42 & 881.37 & 1430.79 & 88.806 & 61.6 \\
\hline Condenser & 10756 & 3785 & 6971 & 199.31 & 94.06 & 293.37 & 96.929 & 23.422 \\
\hline FWT & 2942 & 2110 & 832 & 32.24 & 32.83 & 65.07 & 71.723 & 50.458 \\
\hline Steam turbine & 154431 & 139202 & 15229 & 434.61 & 954.81 & 1389.42 & 90.138 & 68.72 \\
\hline \multicolumn{1}{|c|}{ Total } & $\mathbf{1 8 6 5 1 5}$ & $\mathbf{1 3 9 2 0 2}$ & $\mathbf{4 6 5 5 1}$ & $\mathbf{1 2 2 5}$ & $\mathbf{2 0 9 7 . 2}$ & $\mathbf{3 3 2 2 . 2}$ & $\mathbf{7 5 . 0 4 2}$ & $\mathbf{6 3 . 1 2 7}$ \\
\hline
\end{tabular}

Table 7: Comparison Between the Initial Case and Optimized Case

\begin{tabular}{|l|c|c|c|c|c|c|c|c|c|}
\hline & \multicolumn{3}{|c|}{$\begin{array}{c}\text { Pinch point } \\
{\left[{ }^{\circ} \mathbf{C}\right]}\end{array}$} & \multicolumn{2}{c|}{$\begin{array}{c}\text { Pressure drum } \\
\text { [bar] }\end{array}$} & \multicolumn{2}{c|}{$\begin{array}{c}\text { Objective } \\
\text { function } \\
c_{P, T O T} \\
{[\$ / k J]}\end{array}$} & $\begin{array}{c}\text { CCGT efficiency } \\
\eta_{C C G T}[\%]\end{array}$ & $\begin{array}{c}\text { CCGT gross } \\
\text { power P } \\
{[\mathbf{M W}]}\end{array}$ \\
\hline $\begin{array}{l}\text { Indicial } \\
\text { case }\end{array}$ & 13 & 13 & 13 & 5 & 36 & 140 & 0.09847 & 57.67 & 420.5 \\
\hline $\begin{array}{l}\text { Optimum } \\
\text { case }\end{array}$ & 14 & 4 & 17 & 4 & 37 & 175 & 0.05144 & 58.178 & 424.2 \\
\hline
\end{tabular}

The comparative results of the initial case and the maximum instance were provided in Error! Reference source not found.. It is noticed that the capability raises for $1 \%$, net output power increase for $1 \%$ and the unit exergy cost of the total generated power reduced (objective function) for $47.76 \%$. In the maximized system the exergy elimination reduces 
for, HRSG $18 \%$ and whole system for $7 \%$ condenser $1 \%$, and the total cost rate for system $\left(\dot{Z}+\dot{C}_{D}\right)$ increase from 4855 $\$ / \mathrm{h}$ to $3322 \$ / \mathrm{h}$

\section{CONSCLUSIONS}

In this research, a comprehensive thermodynamic model of the CCGT was conducted. Additionally, a simple optimization method has applied for obtaining the favourable design parameters of the system taking into account limitations. The main purpose in this study involves exergy, economic parameters and performance. A maximization procedure has been carried out with six determination variables.

In the maximization process, the two objectives, minimization of the total cost rate (economic) and maximization of exergetic capability (thermodynamics) were included.

The findings indicates that the exergy elimination cost per hour is reduced by $59.2 \%$, the total cost per hour $\left(\dot{Z}+\dot{C}_{D}\right)$ is decreased by $31.5 \%$, when the capital cost per hour $\dot{Z}$ is increased by $21.46 \%$. In addition, the exergetic efficiency was increased by $2.5 \%$.

\section{NOMENCLATURE}

\begin{tabular}{llll}
$c$ & cost per exergy unit $(\$ / \mathrm{kJ})$ & $S T$ & \multicolumn{1}{l}{ steam turbine } \\
$\dot{C}$ & cost rate $(\$ / \mathrm{s})$ & $T$ & temperature $(\mathrm{C}, \mathrm{K})$ \\
$e$ & specific exergy $(\mathrm{kJ} / \mathrm{kg})$ & $Z$ & capital cost of a component $(\$)$ \\
$\dot{E}$ & exergy rate $(\mathrm{kW})$ & $\dot{Z}$ & capital cost rate $(\$ / \mathrm{s})$ \\
$f$ & exergoeconomic factor & Greek letters \\
$F W T$ & Feed water tank & $\eta$ & isentropic efficiency \\
$h$ & specific enthalpy $(\mathrm{kJ} / \mathrm{kg})$ & $\mathcal{E}$ & exergy efficiency \\
$H P$ & High pressure drum & Subscripts & \\
$I$ & irreversibility & 0 & dead (environmental) state \\
$I P$ & Intermediate pressure drum & $1,2,3 .$. & cycle locations \\
$L P$ & Low pressure drum & $C o n$ & condenser \\
$\dot{m}$ & mass flow rate $(\mathrm{kg} / \mathrm{s})$ & $C C G T$ & Combine cycle gas turbine \\
$P P H$ & High pressure pinch point temperature $(\mathrm{K})$ & $D$ & destruction \\
$P P I$ & intermediate pressure pinch point temperature $(\mathrm{K})$ & $F$ & fuel \\
$P P L$ & Low pressure pinch point temperature $(\mathrm{K})$ & $H P$ & high pressure \\
$\dot{Q}$ & heat transfer rate $(\mathrm{kW})$ & $I P$ & Intermediate pressure \\
$r$ & relative cost difference & $L P$ & Low pressure \\
$S$ & specific entropy $(\mathrm{kJ} / \mathrm{kg} \mathrm{K})$ & $P$ & product \\
SPECO & specific exergy costing & $P H$ & physical
\end{tabular}

\section{REFERENCES}

1. Sahoo PK. "Exergoeconomic analysis and optimization of a cogeneration system using evolutionary programming." Appl Therm Eng, 2008: 28:1580-8.

2. Abusoglu A., Kanoglu M.,. "Exergoeconomic analysis and optimization of combined heat and power production: A review." Renewable and Sustainable Energy Reviews , 2009: 13 - 2295-2308.

3. Lazzaretto A, Tsatsaronis G. "SPECO: a systematic and general methodology for calculating efficiencies and costs in thermal systems." Energy, 2006: 31(8-9):1257-89. 
4. Mohammed S.M., Petrovc V.M.,. "Thermoeconomic optimization of triple pressure HRSG operating parameters for combined cycle plants." Thermal science, 2014.

5. Dincer I., Rosen M.A.,. Exergy: energy, environment and sustainable development. Elsevier, 2013.

6. Baghernejad A, Yaghoubi M,. "Exergoeconomic analysis and optimization of an Integrated Solar Combined Cycle System (ISCCS) using genetic algorithm." Energy Conversion and Management, 2011: 2193-2203.

7. Bejan A., Tsatsaronis G., Moran M.,. Thermal Design and Optimization. New York, NY, USA,: John Wiley and Sons, Inc, 1996.

8. Ahmadi P, Barzegar Avval H, Ghaffarizadeh A, Saidi MH (2011) Thermo economic-environmental multi-objective optimization of a gas turbine power plant with preheater using evolutionary algorithm. Int J Energy 35(5):389-40

\section{AUTHOR'S PROFILE}

Mohammed Saleh Mohammed, Address and affiliation: Mosul University-Engineering collage Mechanical Engineering department, lecturer, Degrees: PhD. In thermal power, 2015 Mechanical Engineering Collage University of Belgrade, Experience: exergy analysis, steam turbine and gas turbine power plant

Publication, Thermoeconomic Optimization of Triple Pressure Heat Recovery Steam Generator Operating Parameters for Combined Cycle Plants, Thermal Science: Year 2015, Vol. 19, No. 2, Pp. 447-460

$\mathrm{PhD}$ thesis titled

\section{Second Author}

Name: Taha Ahmed Abdullah, Address and Affiliation: Mosul University-Engineering collage Mechanical -Engineering department, lecturer, Degrees: PhD. In fluid Mechanic, 2014 Mechanical Engineering Collage University of Belgrade, Experience: Fluid Mechanic, wind tunnel correction

Publication, "Excremental Study of Lift/Drag Ratio Enhancement Using Continuous Normal Suction" Al-Rafidain Engineering Journal; 2012, Vol. 20 Issue 1, pp. 76, February 2012.

Two-Dimensional Wind Tunnel Measurement Corrections by The Singularity Method. // Tehnicki vjesnikTechnical Gazette. 22, 3(2015), pp. 557-565. 